\title{
Strong winds of convective source in Barcelona on 12 June 2012
}

\author{
S. Gonzàlez and R. Pascual \\ AEMET Territorial Delegation in Catalonia, c/ Arquitecte Sert, 1, 08005 Barcelona \\ Received: 23-XI-2012 - Accepted: 11-IV-2013 - Translated version
}

Correspondence to: sgonzalezh@aemet.es

\begin{abstract}
During the afternoon of 12 June 2012 a meteorological phenomenon, characterized by a sudden increase in wind speed and a sharp change in its direction, occurred in the city of Barcelona and surrounding areas. The strong gusts of wind that blew on the Barcelona coastline raised a significant amount of sand from the beaches in the city, which caused a significant reduction in visibility on the coastline, like a small sandstorm. The operational disruption of BarcelonaEl Prat Airport, located a few kilometers southwest of it, was also noteworthy, and led to the abortion of several landings. As indicated, moderate or strong winds affected other regions both north and south of the city of Barcelona, although generally with less intensity. This study has carried out a characterization of the phenomenon and has made a hypothesis about the gust front of convective source, associated to the showers and thunderstorms observed north of the city, as the main cause of the phenomenon. For this purpose, remote sensing data and surface automatic observation have been specifically analyzed. As for the radar data used, there is a novel use of some products such as the Doppler speed spectrum and the wind shear. The early detection of the phenomenon made it possible to notify the airport about the arrival of the gust front in advance, which helped in the track configuration changes that were made. It is, therefore, a good example of nowcasting with immediate practical application.
\end{abstract}

Key words: gust front, convective winds, downburst, aviation hazards, Barcelona

\section{Introduction}

Strong winds of convective origin are one of the biggest risks to aviation. The study of phenomena such as downbursts or gust fronts has been motivated by serious aviation accidents (Wilson and Wakimoto, 2001; Shen et al., 1996; Cubero, 1996). These phenomena mainly affect operations developed at low levels (takeoffs and landings) and produce a sudden change in wind direction that modifies the vertical path of the aircraft while it is subjected to strong gusts of wind and shear. The danger of the phenomenon is that it can be propagated tens of kilometers from the storm and impact against the aircraft in a relatively clear sky (Klock and Mullock, 2001).

Although there is a lot of literature on winds of convective source in the U.S., in Europe there are few studies, most of them focused on winds of convective source embedded in large structures such as straights or cyclones (Lopez, 2007; Pistotnik et al., 2011; Hamid, 2012). VERTIKATOR (Dotzek and Friedrich, 2008) has been the biggest campaign to study winds of convective source in Europe and it compared, through field and radar studies, several cases of downbursts which occurred during the summer of 2002. This paper presents a gust front isolated from the convection zone which occurred on 12 June 2012 and affected Barcelona-El Prat Airport, creating operational problems. However, in this case, the gust front observation and monitoring from different radar products allowed the Forecasting and Monitoring Group of the Territorial Delegation and the Airport authorities to be alerted, who were then able to take appropriate action. 


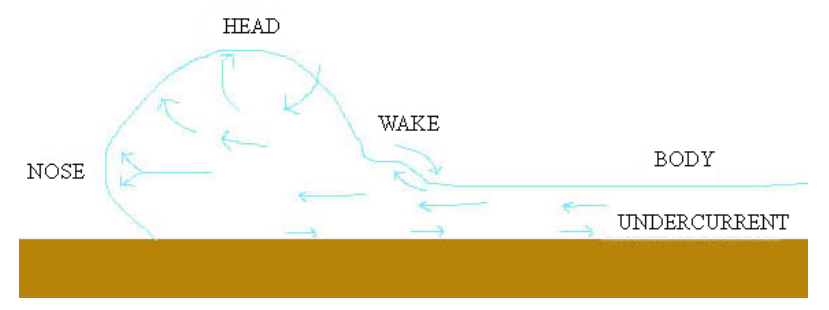

Figure 1. Conceptual model of density current moving from right to left. Based on Mueller and Carbone (1987).

Therefore, in this study we characterize the phenomenon and its environment and confirmed its diagnosis as gust front. Moreover, given the implications observed in the operation of Barcelona-El Prat Airport, the conclusions section will give some useful guidelines for the forecasting and monitoring of the phenomenon.

\section{Characterization of gust fronts}

Gust fronts are winds of convective source that can result in strong surface gusts. They occur at the boundaries between the outputs of cold, dense air from descents that are generated within storms and the surrounding air. When reaching the ground, the downdrafts are forced to move horizontally around the center of the storm although with privileged motion directions in the direction of the storm motion. The gust fronts behave as density currents and several parts can be distinguished in them (Mueller and Carbone, 1987) (Figure 1).

To produce a density current it is necessary to have negative buoyancy within the parent convective focus. This negative buoyancy is supported by two distinct mechanisms (Johns and Doswell III, 1992):

- Cooling by evaporation and sublimation of hydrometeors in the presence of an unsaturated layer.

- Dragging due to hydrometeor discharge.

Intense downdrafts are classified in two prototypes according to their thermodynamic profile: dry and wet. This classification has been mainly used to describe downbursts, but it is assumed to be equally valid for gust fronts from these downdrafts. "Dry" downdrafts have little or no surface precipitation. The thermodynamic profile in which they are developed is characterized by a deep dry layer at low levels in an inverted V-shape that has an adiabatic gradient from the surface to medium levels (Wakimoto, 1985). Convection is weak and clouds have high cloud bases. These downdrafts are produced mainly by evaporative coolinge (Markowski and Richardson, 2010). "Wet" downdrafts are the most common ones and are generated in highly unstable environments with deep moist layers (Johns and Doswell III, 1992). They are produced by a combination of two mechanisms, evaporation and dragging.

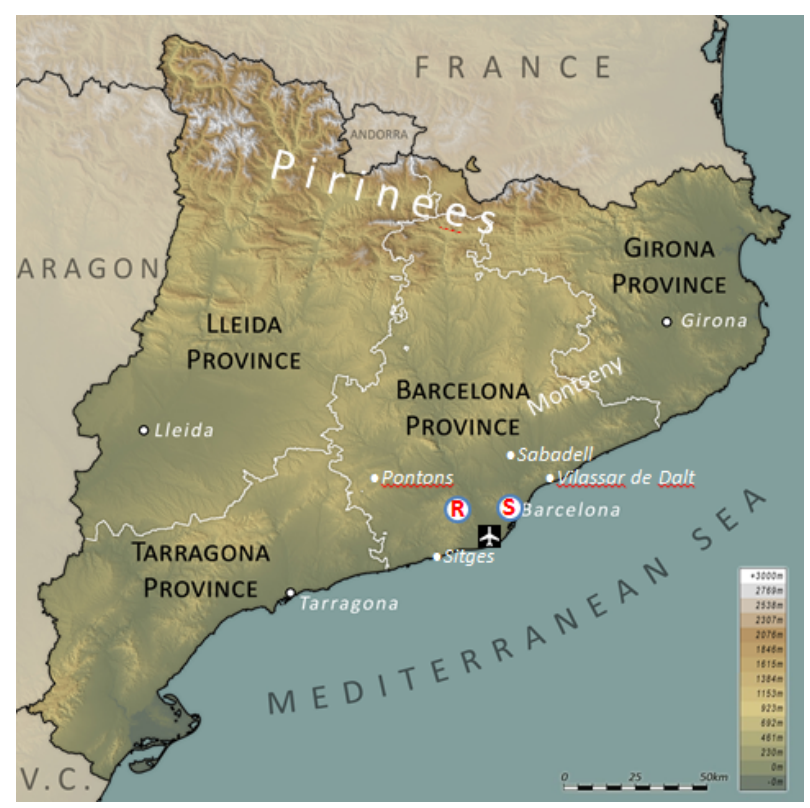

Figure 2. Physical map of Catalonia and location of some points of interest mentioned in the text. The white circles with the letters $\mathrm{R}$ and $\mathrm{S}$ indicate the position of the radar and radio sounding respectively.

Observationally, both types are manifested as sudden changes in wind speed (vertical and horizontal component) and direction, going usually from a situation of flow into the storm to flow out of the storm (Mueller and Carbone, 1987). There is also a drop in temperature, an increase in relative humidity and a sudden increase in pressure. Moreover, the front of the density current forces the warm and less dense air that surrounds it to rise and, if the environment is sufficiently moist, the formation of arcus type cumuliform clouds and new storms will be possible.

\section{Data used}

In this paper we basically used the tools and data available from routine operational forecasting.

The remote sensing data used are satellite imagery from Meteosat MSG2 or 9, and the data generated by the radar that AEMET has in Puig de les Agulles, about $20 \mathrm{~km}$ southwest of the city of Barcelona (Figure 2), at an altitude of $654 \mathrm{~m}$ asl. It is C-band $(\lambda=5,4 \mathrm{~cm})$, and has a range of $240 \mathrm{~km}, 21$ elevations and a spatial resolution of $1 \mathrm{~km}$.

As for the numerical models surveyed, we have worked with the outputs of the ECMWF deterministic model T1279, with a horizontal spatial resolution of approximately $16 \mathrm{~km}$, and with the outputs of the $0.05^{\circ}$ HIRLAM model, with a horizontal spatial resolution of approximately $6 \mathrm{~km}$.

Other data used were the Barcelona radio sounding, launched by the Meteorological Service of Catalonia (SMC), data from the network of automatic weather stations of the SMC and the AEMET and data from the automatic observing system that AEMET has in the airport. 

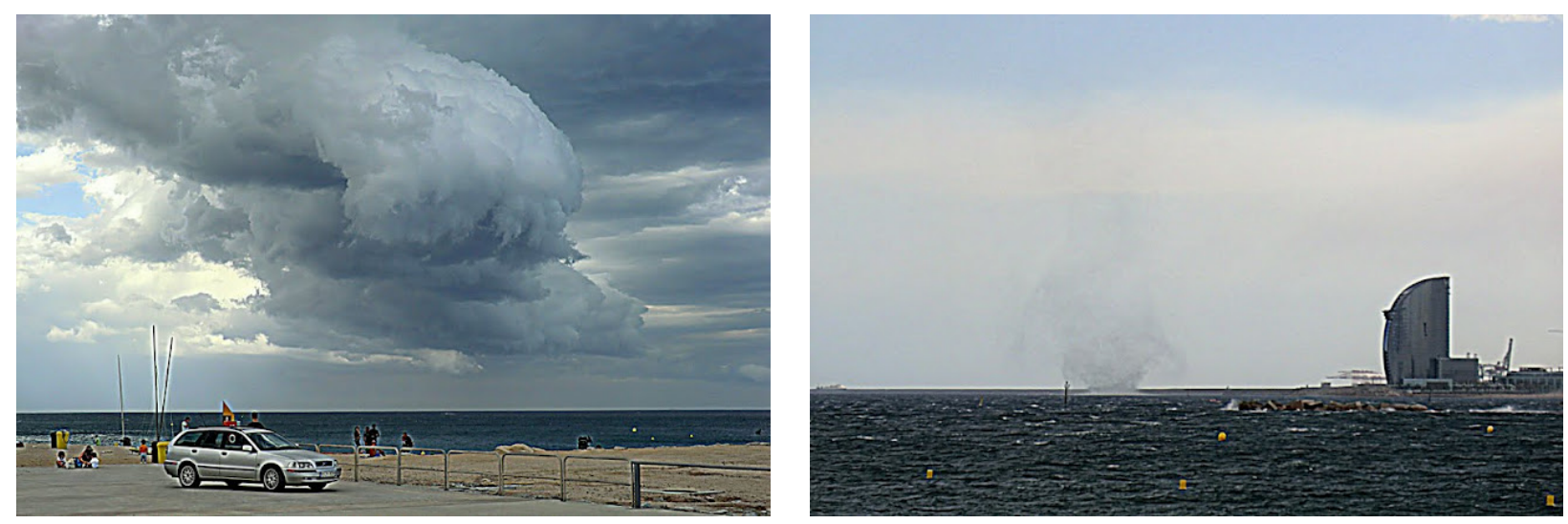

Figure 3. Left (a): arcus-type cloud observed on the beach in Barcelona during the passage of the gust front. Right (b): small vortex observed over the sea off the port of Barcelona, coinciding approximately with the passage of the gust front. Author: Ramón López.

\section{Analysis of observations}

During the afternoon of 12 June 2012, in an area of about $30 \mathrm{~km}$ around Barcelona there was a meteorological phenomenon characterized by a sudden change in wind speed and direction at various weather stations. The maximum gusts were reached in the city of Barcelona at 16:05 UTC, coinciding with the passage of a cloud band identified as arcustype (Figure 3a). There was a gust of $84 \mathrm{~km} \mathrm{~h}^{-1}$ from eastnortheast in the anemometer that the Territorial Delegation of the Spanish National Meteorological Agency in Catalonia has on the roof of the building in which it is located. The strong gusts raised large amounts of sand from the beaches nearby, thus generating a mini-sandstorm that, for a few minutes, reduced visibility to a few meters.

Non-tornadic vortexes with vertical axes were also observed on the sea, rising from the surface and with no apparent connection to the cloud mass (Figure 3b). Furthermore, the gusts were accompanied by a sharp rise in the relative humidity, from $32 \%$ to $62 \%$ and a fall in temperature from $26^{\circ} \mathrm{C}$ to $21^{\circ} \mathrm{C}$ (Figure 4 ).

The gust front hit other locations in the coastal and precoastal regions of Barcelona, for example, Sabadell Airport recorded a gust of northeast wind of $49 \mathrm{~km} \mathrm{~h}^{-1}$, in Parets del Vallès there was a gust, also northeastern, of $53 \mathrm{~km} \mathrm{~h}^{-1}$, while in Vilassar de Dalt the observed gust was $48 \mathrm{~km} \mathrm{~h}^{-1}$ (see Figure 13).

The sudden change in wind direction also affected Barcelona-El Prat Airport, about $12 \mathrm{~km}$ southwest of the Territorial Delegation. Hours before the passage of the gust front, there was a stationary wind from the southwest in all threshold with average speeds of between 30 and $40 \mathrm{~km} \mathrm{~h}^{-1}$. The temperature was around $26-27^{\circ} \mathrm{C}$ while the pressure was maintained at $1010 \mathrm{hPa}$. The only variable that showed changes during this previous period was moisture, which showed a tendency to decrease from $45 \%$ to values of $30 \%$ within 2 hours.

The emergence of the front generated an uneven wind change at the different wind sensors located at the runway threshold of the airport. The passage of the gust front was seen primarily at about 16:20 UTC on the threshold located in the northeastern sector (25R and 20), abruptly changing the wind direction from SW to NE with no significant changes in wind speed appreciated. By 16:30 UTC, the front passed through the pierhead 07L changing the wind direction to NNE.

The passage of the gust front started with the northernmost threshold, while those located in the south area (02, $07 \mathrm{R}$ and $25 \mathrm{~L}$ ) of the airport showed a decrease in wind speed and variable direction for about 30 minutes. These moments were the most critical for the operation of the airport due to the intense horizontal shear existing in less than $2 \mathrm{~km}$, with completely opposite winds and strong wind gusts (Figure 5). Finally, a wind input from the east that occurred behind the front eventually affected the rest of the threshold at 17:00 UTC. At that time, the wind strength increased again in the threshold located in the south and the conditions in the whole airport became homogeneous again, establishing a $50^{\circ}$ wind with average speeds between 25 and $40 \mathrm{~km} \mathrm{~h}^{-1}$.

The wind change had an impact on the operation of the airport: it caused the abortion of several landings, two of them below 200 meters, a track change maneuver had to be done, which involved paralyzing the air traffic for half an hour and both aircrafts had to land at nearby airports. Two other airplanes had to fly over the airport for half an hour during the airport configuration change.

\section{Synoptic and mesoscalar environment}

The synoptic situation was defined by the passage of a relatively shallow, long wave geopotential trough from west to east, present at medium and high levels $(300,500$ and $700 \mathrm{hPa}$ ). At $12 \mathrm{UTC}$, a maximum of west wind of $100 \mathrm{kt}$ with cyclonic curvature was present at $300 \mathrm{hPa}$ (Figure $6 \mathrm{a}$ ), between the northeast of the Iberian Peninsula and the Balkans, with Catalonia being in the right entry area of this maximum. This wind maximum went slowly towards 

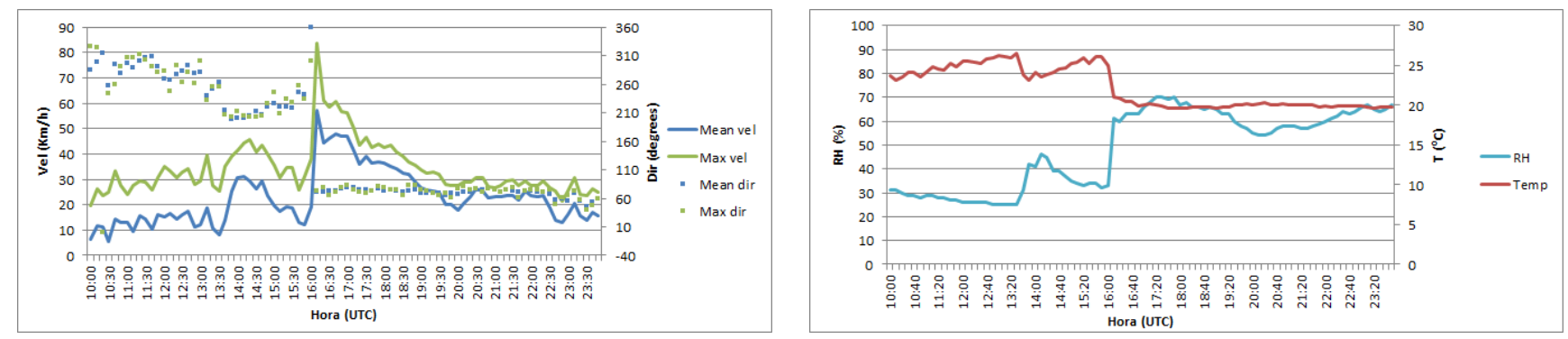

Figure 4. Ten-minute data from the station located on the terrace of the Territorial Delegation in Barcelona for 12 June 2012 . Left: Direction and speed of the average wind and maximum gust recorded by the station. Right: relative temperature and humidity. Note the abrupt change in weather conditions after the passage of the front at 16:05 UTC.

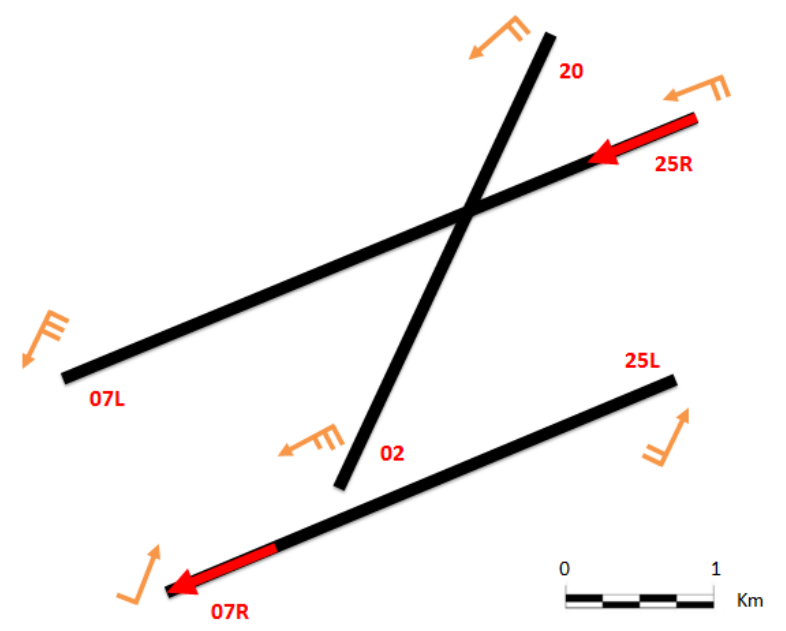

Figure 5. Wind gusts in the 6 airport threshold at Barcelona-El Prat Airport between 16:40 and 16:50 UTC, moments of maximum horizontal wind shear. The long red arrows indicate the landing and takeoff directions configured on the time prior to making the change of track configuration.

the east in some hours. At $500 \mathrm{hPa}$ the passage of the trough occurred alongside a negative thermal advection that placed a heat wave over the study area with temperatures between $-16^{\circ} \mathrm{C}$ and $-20^{\circ} \mathrm{C}$ over the vertical of the Pyrenees (Figure 6b).

On surface (Figure 6c) the synoptic situation was defined by a moderate flow from the north, partly reinforced by the presence of a low in the Gulf of Genoa. This means that the mesoscale analysis (Figure 7) shows a moderate westerly flow in the south and west of Catalonia and a much weaker and undefined flow in the rest of the region, produced by a low to the lee side of the Pyrenees that is recurrent under postfrontal North situations (Pascual and Callado, 2002) such as this one. This low is usually associated with convergence in central precoastal Catalonia (Figure 6c), and, if the other elements are present, with the development of convection.

Thus, it could be seen that in the northeast of Catalonia the predominant winds are from the east or southeast, of ma- rine origin, that converge with the aforementioned westerly winds generating convergence areas. The analysis at 16 UTC shows these areas of convergence in the interior of Girona, on the northern coast of the province of Barcelona and in the northern half of the province. In the analysis of 19 UTC, the convergence zone had shifted to the south and west due to the stronger penetration of winds from the east blowing north of Barcelona city, that affect much of the provinces of Barcelona and Girona.

\section{Thermodynamic conditions of the environment}

The Barcelona radio sounding analysis at 12 UTC showed very dry and relatively cold medium-high levels, and a sharp inverted V-shape at medium and low levels, in other words, a wetter intermediate zone ( $700 \mathrm{hPa})$ and very dry low levels (Figure 8). The dryness of low levels is partially justified by the west component of the wind in that area, which indicates that this analysis is representative of the air mass to the south of the convergence zone. Towards the $500 \mathrm{hPa}$ there was a thermal inversion that generally prevented a profound development of the convection. A significant element is the presence of an adiabatic gradient below $700 \mathrm{hPa}$, which allowed free air circulation in the vertical wind in that layer. This is relevant for the development of gust fronts as it allows the air in a shower or storm to drop from medium levels without losing energy.

As for the vertical wind profile, it shows no directional shear but a remarkable shear by altitudinal increase of the wind speed, with a wind maximum at $300 \mathrm{hPa}$ and a CIZ (0$6 \mathrm{~km}$ ) index of $37 \mathrm{~m} \mathrm{~s}^{-1}$, a value that is quite high, which in the presence of enough instability allows the separation of the upstream and downstream current and the generation of supercells (Rasmussen and Blanchard, 1998).

According to the radio sounding, all the thermodynamic conditions required for the development of dry microburst were met (Wakimoto, 1985; McCann, 1994):

- V-shape sounding at low levels.

- Deep dry layer with adiabatic gradient. 


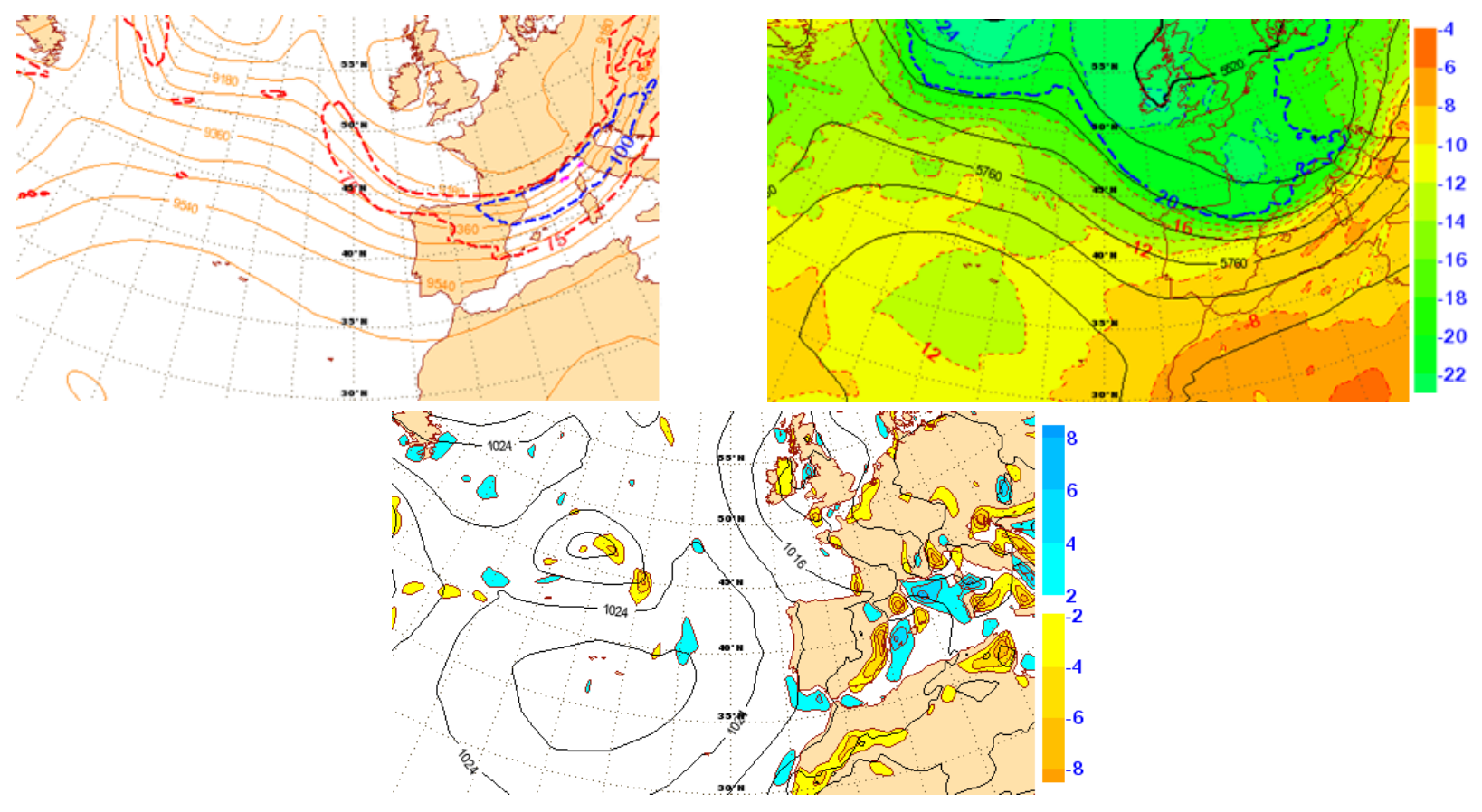

Figure 6. Synoptic analysis of 12 June 2012 at 12 UTC of the ECMWF operational deterministic model. Top left (a): isohypses (orange) and isotachs of $75 \mathrm{kt}$ (red) and $100 \mathrm{kt}$ (blue) at $300 \mathrm{hPa}$. Top right (b): isohypses (black) and isotherms (shaded) at $500 \mathrm{hPa}$. Bottom (c): isobars (black) and surface divergence (shaded, with warm colors for negative values).

- Little instability and high or nonexistent Level of Free Convection.

This case shows some differences with bibliographic references: the dry and adiabatic profile layer has a smaller depth probably due to the lower "continentality" of the Barcelona radio sounding regarding the US locations where the studies have been conducted.

A first approach to the problem of calculating the maximum gusts that can be registered associated with microbursts (and the resulting gust fronts) is the calculation of the WINDEX index (McCann, 1994). This index can be calculated with radio sounding data. The formula for calculating the WINDEX (WI) is:

$W I=5\left[H_{M} R_{Q}\left(\Gamma^{2}-30+Q_{L}-Q_{M}\right)\right]^{0.5}$

where $H_{M}$ is the isozero height above the ground $(\mathrm{km}) ; R_{Q}$ is $Q_{L} / 12$ but not $>1 ; \Gamma$ is the vertical gradient in ${ }^{\circ} \mathrm{C} \mathrm{km}^{-1}$ from the surface to the melting level; $Q_{L}$ is the mixing ratio in $\mathrm{g} \mathrm{kg}^{-1}$ averaged on the first kilometer above the surface and $Q_{M}$ is the mixing ratio in $\mathrm{g} \mathrm{kg}^{-1}$ at the melting level.

WI gives the value of the maximum gust in knots. The value obtained from the available data has been $42.3 \mathrm{kt}$, which is very close to the maximum gust recorded at the various automatic stations. It should be emphasized that the WINDEX is designed for microbursts and not for gust fronts, but it is clear that the maximum gusts that go with them are related to downstream speeds in storms.

Some thermodynamic indexes of the sounding show relatively low values (TT $=46^{\circ} \mathrm{C}$ and $\mathrm{K}=21^{\circ} \mathrm{C}$ ), although the analysis of the model at a synoptic and a mesoscale scale show higher rates (a TT of 48 to $56^{\circ} \mathrm{C}$ and a $\mathrm{K}$ from 28 to $32^{\circ} \mathrm{C}$ ) in half northern Catalonia. Such a sharp difference between the values in the northern half and the southern half is due to the higher humidity in lower layers north of the convergence zone as opposed to the dryness shown by the south area. These differences between north and south can also be observed in the CAPE value, null in the southern half as the Barcelona sounding shows, while in the northern half it takes values of 200 to $300 \mathrm{~J}$. Thus, the values of $\mathrm{K}$ and TT indexes are comparable to the values during the VERTIKATOR campaign (Dotzek and Friedrich, 2008); while the value of CAPE is significantly lower due to the altitude at which convection starts and the low height of the thermal inversion. All thermodynamic indexes are also lower than those found in other severe weather events in Catalonia (Bech et al., 2007; Pineda et al., 2009).

From the temperature data provided by the aircraft landing at Barcelona-El Prat Airport, it has been found that the shape of the vertical profile of temperature from the 12 UTC radio sounding remained at least until early afternoon, until the passage of the gust front. Thus, data from an airplane at 15:41 UTC (Figure 8b) showed that the vertical temperature and wind gradients remained unchanged from the 12 UTC radio sounding, and possibly the vertical profile of moisture as well. Other airplane data, corresponding to 16:57 UTC (Figura 8c), after the passage of the front, show a significant change below $800 \mathrm{hPa}$. There is an air cooling in the lower layers and the wind profile also changed, establishing east- 


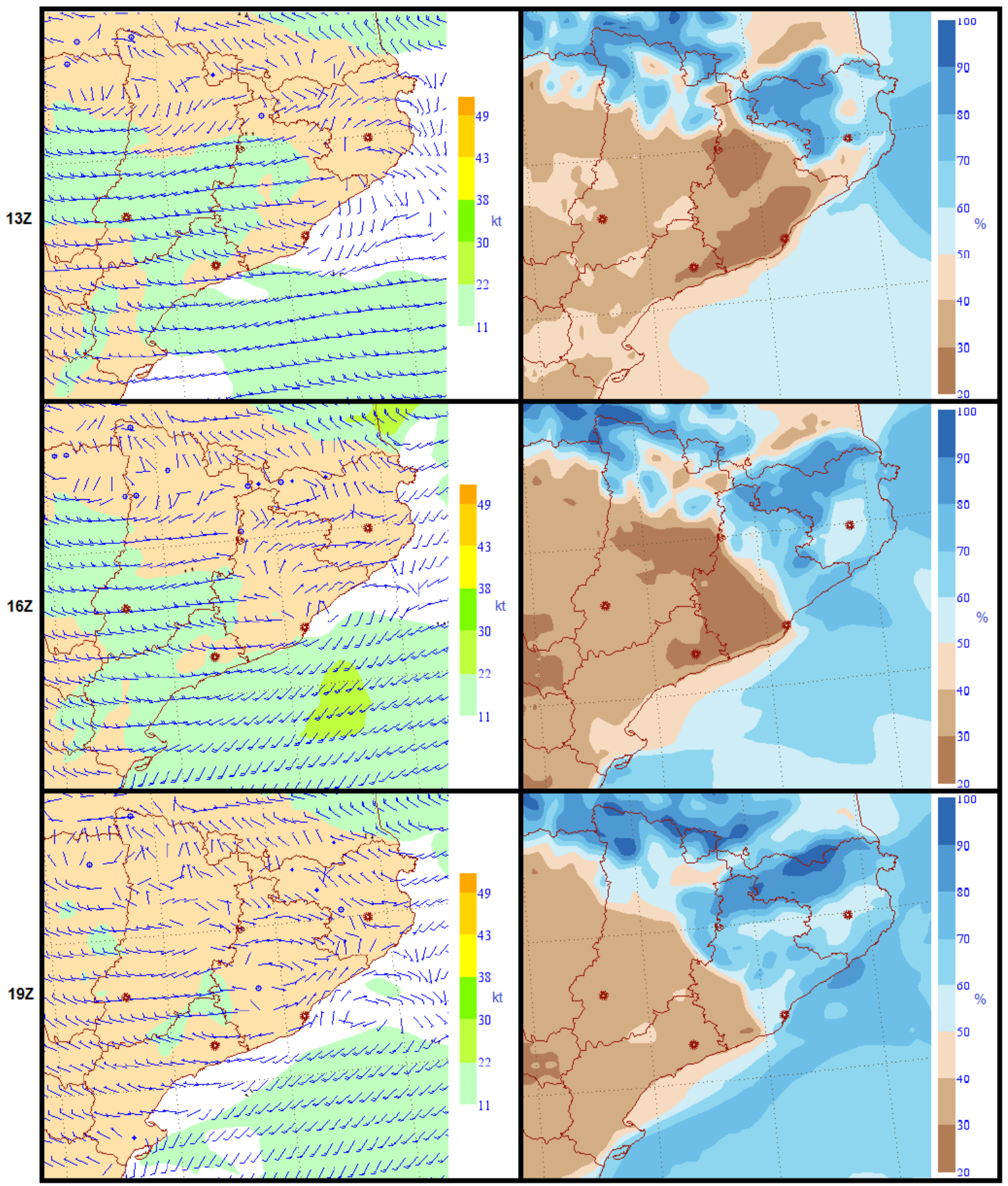

Figure 7. Mesoscale Analysis of 12 June 2012 of the 0.05 HIRLAM model. Left: average wind speed at $10 \mathrm{~m}$ (wind arrows) and isotachs (shaded). Right: Relative humidity at $2 \mathrm{~m}$. From top to bottom: 13 UTC, 16 UTC and 19 UTC. In the image sequence, the moving of the convergence zone south coinciding with a discontinuity in the relative humidity is shown. 


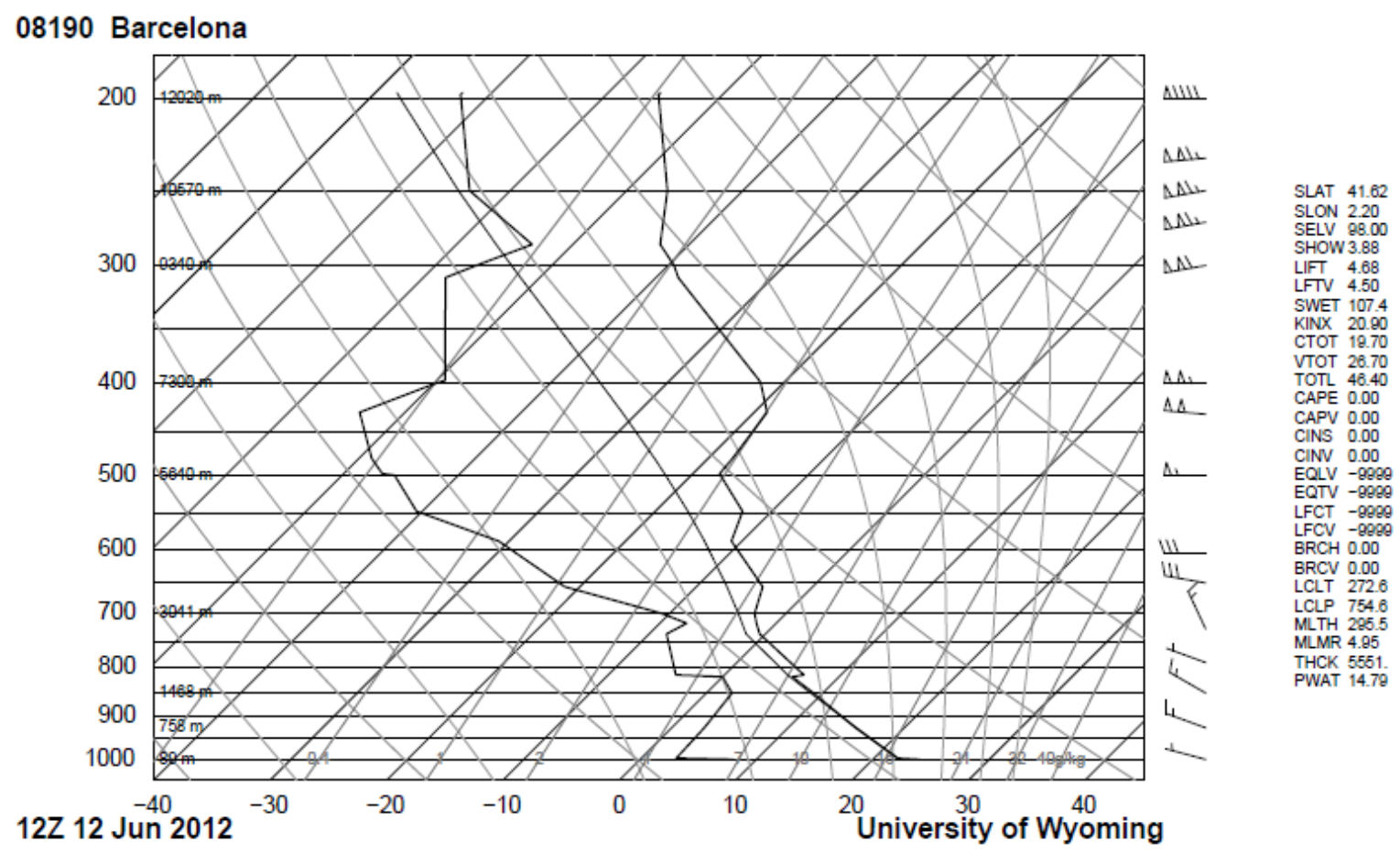

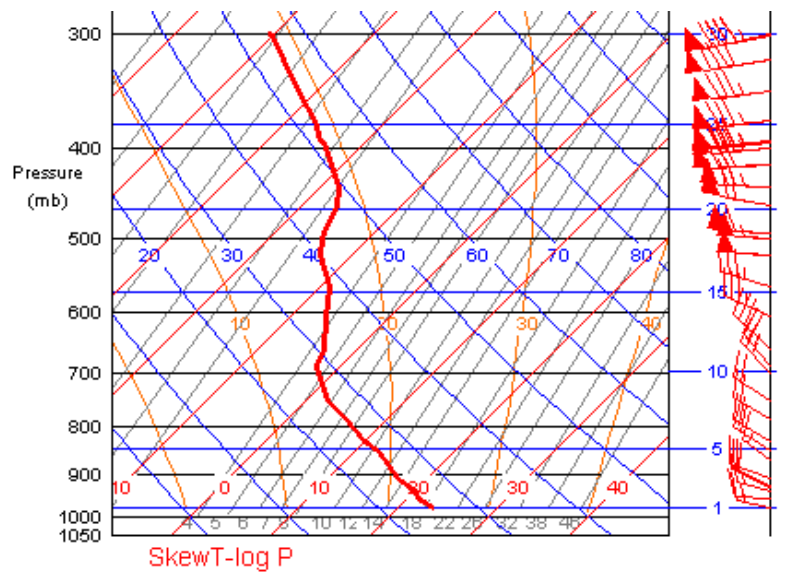

NOAA / ESRL / GSD

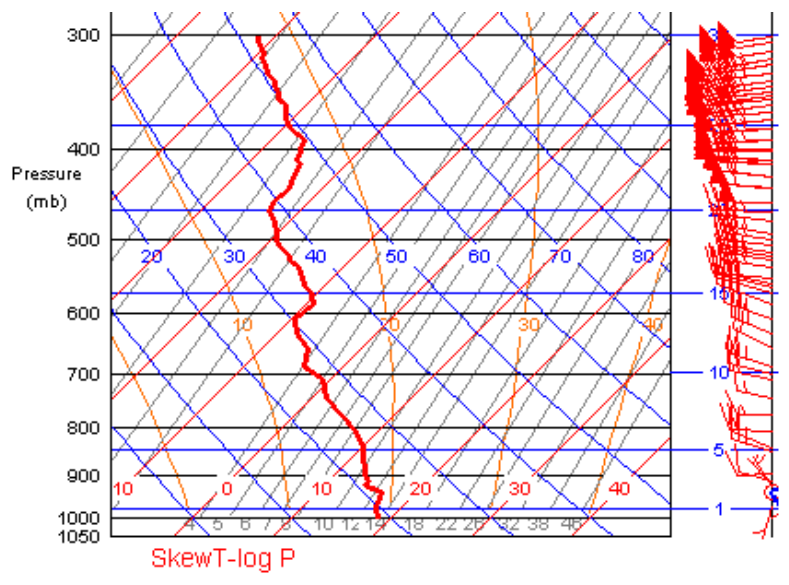

NOAA / ESRL / GSD

Figure 8. Top (a): Barcelona radio sounding SMC made on 12 June 2012 at 12 UTC. The survey presents a strong inversion above the level of $500 \mathrm{hPa}$ and a strong wind shear. This vertical structure promotes convection at height and free movement of the wind in the vertical. Bottom: RAOB survey conducted by planes that landed at the Barcelona-El Prat Airport. Bottom left (b): RAOB of 15:41 UTC. Bottom Right (c): RAOB of 16:57 UTC. Note how thermodynamic conditions change at low levels after the passage of the gust front. Source: University of Wyoming and AMDAR (NOAA).

erly winds in the lower layers whilst maintaining the west wind in the upper layers. It could be concluded that the difference between the air masses were established only at low levels.

\section{Analysis of the remote sensing phenomenon}

The detailed observation of both radar images and HRV images (high resolution channel visible from the MSG2 satellite) shows the formation, movement and evolution of a cloud band with a very faint signal in the Surface Rainfall Intensity (SRI) radar product that has been associated with a gust front. Indeed, SRI images show a thin arched line (Figure 9a). Although at first evaluation, this could be considered noise in the image, spatial and especially temporal continuity suggest that this is an actual weather event (Klingle et al., 1987). The same phenomenon is observed in the HRV image (Figure 9b), a small cloud band at the southern end of the storm moving to the south-southwest and unlinking itself 

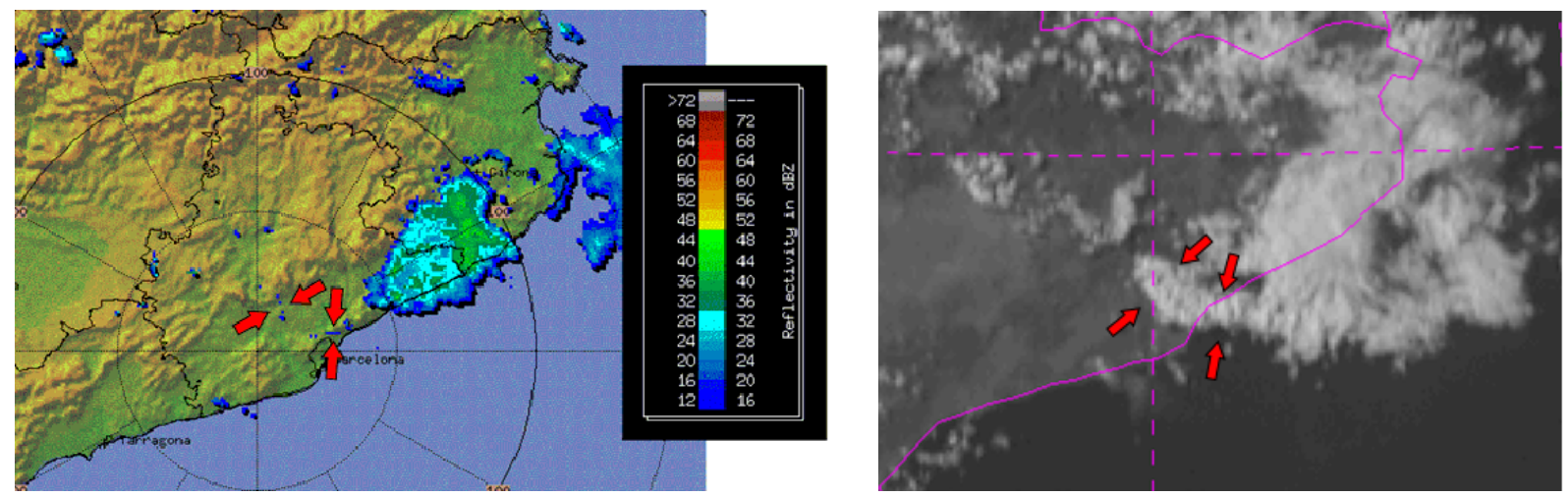

Figure 9. Left (a): SRI image of 12 June 2012 at 15:40 UTC. Right (b): HRV image of the MSG2 satellite on 12 June 2012 at 15:45 UTC. The red arrows indicate the thin line and the cloud band associated with a gust front. Note how they match the same meteorological phenomenon. The sequence of images shows how the structure is formed to 14:40 UTC and moves initially in N-S direction, curving at 15:10 UTC following a NE-SW displacement.

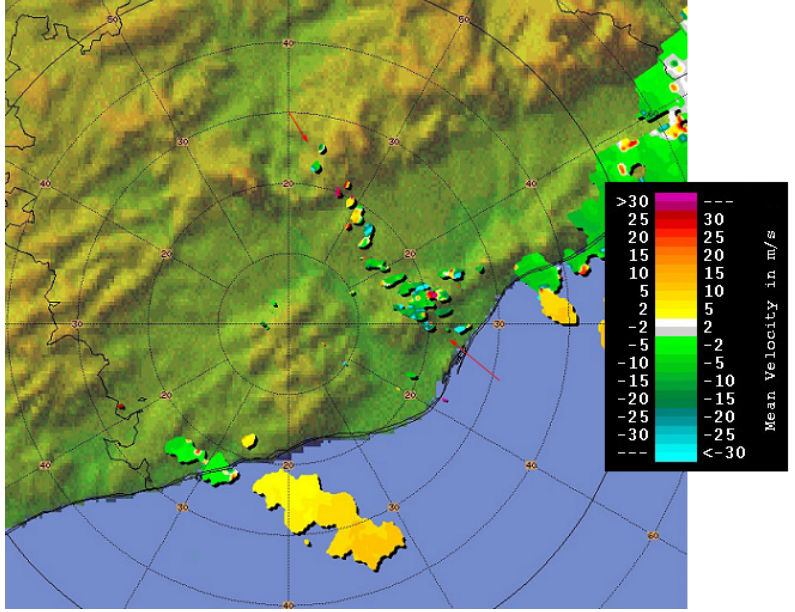

Figure 10. Image of Doppler radial speed at an elevation of $0.5^{\circ}$, on 12 June 2012 at 15:46 UTC. The Red Arrows indicate the band diagnosed as gust front. The radial speed areas of the opposite to the front movement could be vertical axis vortices (Mueller and Carbone, 1987).

from the main convective cloudiness.

SRI and HRV products are insufficient to detect this phenomenon unambiguously and to follow its evolution, because it is very easy to confuse them with noise or clouds not associated with any severe phenomenon. That is why it is necessary to use radar products obtained with the Doppler radar system. These products were calculated from the IRIS $^{T M}$ software and a more detailed description of each product can be consulted in Sigmet (2011). The set of Doppler products mentioned below determined, according to the criteria established by Klingle et al. (1987) that this phenomenon was a gust front.

- The Doppler radial wind at $0.5^{\circ}$ elevation shows an approximately aligned echo signal with radial speed to- ward the radar in its early stages. Negative radial speeds (toward the radar) were between -5 and $-20 \mathrm{~m} \mathrm{~s}^{-1}$, being the highest located in the central area of the band (Figure 10). This line acquired a better shape as it approached the radar. This could be due both to the evolution of the line itself or to a radar observation that became better due to the lower elevation of the beam (Klingle et al., 1987). It is remarkable that within the band there were small areas with positive radial speed, i.e., away from the radar, that could be vertical axis vortices developed along the gust front, as shown in the references (Mueller and Carbone, 1987).

- Another radar product considered by the references to be useful for the detection of gust fronts is the spectrum width of measured radial speeds (Klingle et al., 1987). This product provides a measure of the flow turbulence wherever there is sufficient concentration of precipitating particles. The line observed in the images of this product gained size and appearance between 15:00 and 16:00 UTC (Figure 11) when the band shows relatively high values of turbulence (up to $4 \mathrm{~m} \mathrm{~s}^{-1}$, values slightly lower than those measured by Klingle et al. (1987) in field studies carried out in the large US plains), which decrease rapidly after this time (up to $2 \mathrm{~m} \mathrm{~s}^{-1}$ ).

- The last product that enabled the detection and monitoring of the gust front is the so-called SHEAR in the radar software used. This product shows the horizontal wind shear (absolute value of the radial and azimuthal shear) wherever there is a perceptible radar signal, and has been used for the development of products for the identification of convective source winds (Saltikoff et al., 2004). Since a gust front is just a structure in which there is a significant change in the wind direction and speed, it is reasonable to think that this type of structure can be identified in this product. On the observed line (Figure 12), shear values exceed the threshold of $2 \mathrm{~m} \mathrm{~s}^{-1}$ per km established by Saltikoff et al. (2004), 


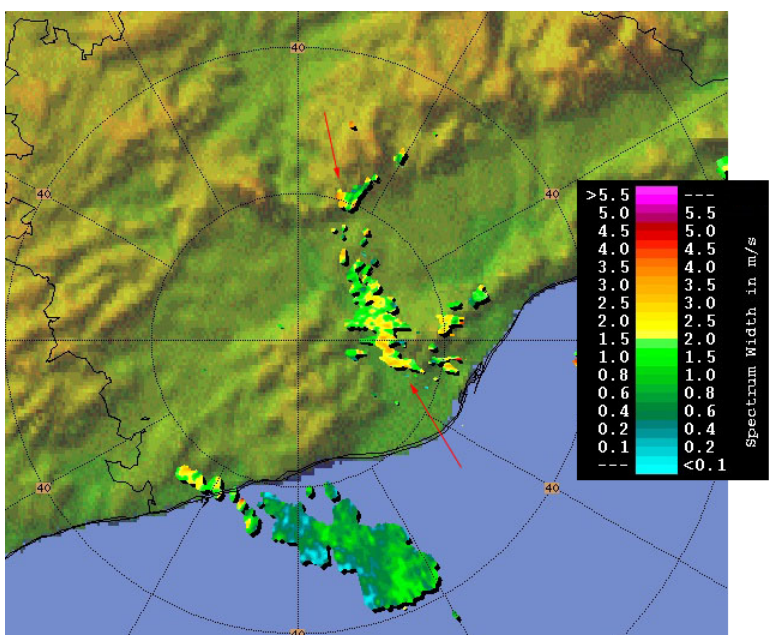

Figure 11. Image of the Doppler radial speed spectrum width on 12 June 2012 at 16:06 UTC. The Red Arrows indicate the band diagnosed as gust front. Values of up to $4 \mathrm{~m} \mathrm{~s}^{-1}$ which indicate a high flow turbulence were observed wherever the attack area of the gust front was present. The turbulence was decreasing as the front was dissipated.

appearing to be rather noisy. It should be highlighted that this product is the best for showing the differential gust front of precipitation areas.

The estimated propagation speed of the gust front from the analysis of these radar products is $20 \mathrm{~km} \mathrm{~h}^{-1}$. The maximum length of the gust front can be estimated at about $50 \mathrm{~km}$ but it is variable in time and difficult to estimate accurately, because its ends are precisely the worst observed areas from the radar.

\section{Development and evolution of the gust front}

A study of the evolution of the gust front was done from remote sensing and surface observation data. Observations at 14 UTC show moderate westerly winds throughout Catalonia except the northeast quadrant, where the flow was easterly and weak. Consequently, a very well defined boundary was set, which divided the land into a dry area associated to offshore wind and another humid area due to the presence of winds of marine origin. On the border between the provinces of Barcelona and Girona the defined border coincided with a convergence zone at low levels.

Convection was developed across the northern third of Catalonia and especially in the convergence zone, within which the storms had a little shift southward. IR satellite images, as well as the echo top product of the radar, suggest that the developments were not very deep. All the showers moved northwest to southeast, according to the rector flow at $700 \mathrm{hPa}$. In the stations in the Pyrenees and Western PrePyrenees (Lleida) and generally in the northwest quadrant of Catalonia there was a temporary change in wind direction

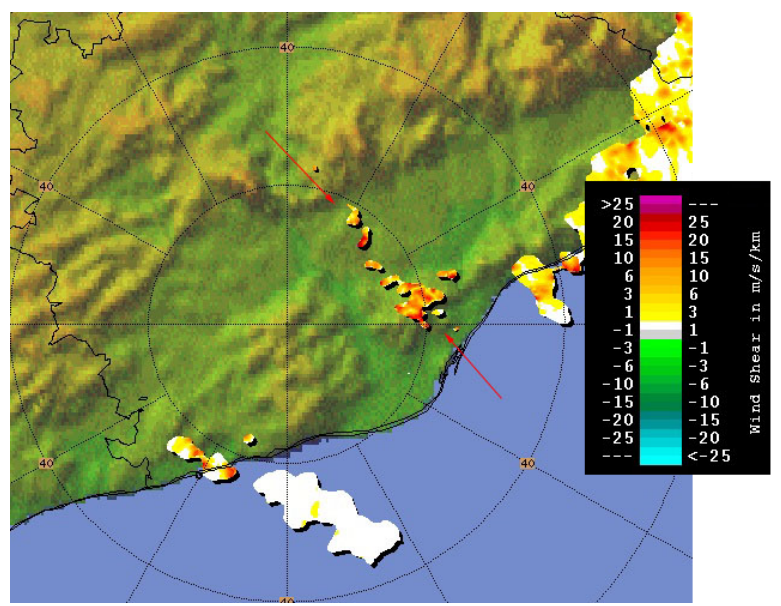

Figure 12. Doppler image of the horizontal wind shear on 12 June 2012 at 15:46 UTC. The red arrows point to the band diagnosed as gust front. The front shows shear values ranging from $5 \mathrm{~m} \mathrm{~s}^{-1}$ per $\mathrm{km}$ to $20 \mathrm{~m} \mathrm{~s}^{-1}$ per $\mathrm{km}$, where the convective precipitation areas are well distinguished.

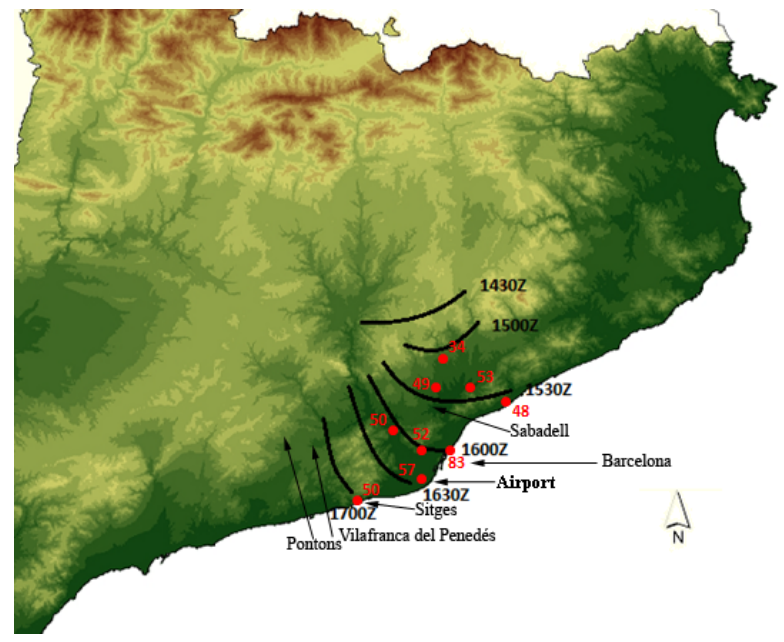

Figure 13. Advance of the gust front (black line) that affected Barcelona on 12 June 2012 made from observation and remote sensing data where the initial north-south movement and the shift towards the southwest that happened at about 15:10 UTC can be observed. By 17:00 UTC the front had dissipated. The time for each position is indicated in black every 30' and the value of the maximum gust recorded at different observatories in $\mathrm{km} \mathrm{h}^{-1}$ in red.

associated with gust micro-fronts produced by convection, going from west to north in the wake of the showers to return later to the west.

The most active core, with radar reflectivity of the surface slightly above $50 \mathrm{dBZ}$, was generated to the northwest of the Montseny massif where interaction with the orography, as well as its location in the aforementioned convergence zone, contributed to its development. Through various remote sensing products it has been determined that the gust 
front was created in this core, being eventually separated and moving further south.

The gust front, which at first moved from north to south, suddenly changed its direction to southwest at 15:10 UTC. The time of the redirection suggests it may have been due to it merging with another gust front which emerged from the Montseny storm.

From 15:30 UTC onwards, along with the passage of the front, a significant change in the wind was seen in the data of the stations located in the northeast of the province of Barcelona, which was to spread to the southwest stations. Overall, taking into account local particularities, the progress of the gust front can be seen in the coastal and pre-coastal stations of Barcelona until 17 UTC: at this time it seems that the gust front dissipated in the approximate longitude of Sitges , a town about $36 \mathrm{~km}$ south of Barcelona (Figure 13).

The passage of the gust front in turn resulted in the progressive setting of wind from the east. This transition was still happening, albeit more slowly, at 18:00 UTC in Vilafranca del Penedès and at 19:10 UTC in Pontons, towns in the southern pre-coastal area of Barcelona.

Once the new "stationary" conditions were established, it is confirmed that the convergence line between east and west had shifted from the east of the province of Barcelona to the west of it, as also shown by numerical models and very short term forecasts. In summary, the detailed analysis of the situation suggests that the interaction between gust fronts of convective source and the entry of a subsynoptic eastern flow affected the eastern and northern half of Catalonia, which could have influenced the direction taken by the front. This interaction was such that where the gust front was present, the penetration of the subsynoptic northeast was faster and more efficient, opening a channel to facilitate the penetration.

\section{Conclusions}

During the afternoon of 12 June 2012, strong and very strong gusts of northeast wind were recorded in various parts of the pre-coastal area and central coastline of Catalonia. The presence of showers and a storm in areas north of the city of Barcelona suggested from the beginning that the phenomenon was due to the arrival of the gust fronts generated by these storms. The fine analysis carried out in this study confirms this hypothesis. According to the soundings analyzed, the previous thermodynamic conditions established a favorable environment for this phenomenon. However, the setting of wind from the east after the passage of the gust front suggests that the presence of a subsynoptic easterly flow could have also played a key role, somehow coupling the passage of the gust front with the advancing west and south of this flow.

The amount of sand raised in the beach area of the city of Barcelona and the consequent reduction of visibility were a circumstantial consequence of the combination of strong wind and the sand type. In addition, the conditions at
Barcelona-El Prat Airport were particularly unfavorable for its operability due to the progressive advance of the gust front that set up, for a few minutes, very different weather conditions, particularly the wind, at different runway threshold.

From the point of view of the very short term forecast of the phenomenon, the following aspects must be highlighted: convection is associated to gust fronts that can be more or less intense, usually embedded in the convective system itself but occasionally separated from it. On this occasion, the thermodynamic sounding at 12 UTC in Barcelona showed a lower adiabatic layer favoring descent and consequently the possibility of strong gust fronts. These thermodynamic conditions prevented the isolated gust front from creating convective cores, making it difficult to detect. Gust fronts tend to move in the forward direction of storms ahead of them, although this may vary due to interactions with subsynoptic flows. Accordingly, in situations with convection in the vicinity of the point of interest, such as an airport, it is advisable to analyze the radar products, such as Doppler speed and especially the SHEAR product that shows horizontal wind shears, which appear by definition in gust fronts. Identifying the thin line in the field of radar reflectivity appears to be more difficult.

Acknowledgements. To Francisco Martín Leon, head of the Forecasting Techniques and Applications area of AEMET, for his insightful comments, corrections and suggestions. To Esteban Abellán and Alfons Callado, from the DT of the AEMET in Catalonia for their invaluable help in collecting data. To Joan Arús for the idea of checking the AMDAR aircraft soundings and the information provided on Rafael Cubero and his studies and letters about the plane crash at Granada Airport in 1992.

\section{References}

Bech, J., Pascual, R., Rigo, T., Pineda, N., Lopez, J. M., Arús, J., and Gayà, M., 2007: An observational study of the 7 september 2005 Barcelona tornado outbreak, Nat Hazards Earth Syst Sci, 7, 129-139, doi: 10.5194/nhess-7-129-2007.

Cubero, 1996: Cortante vertical del viento o cizalladura a niveles bajos, Low Level Wind Shear, II Jornades de Meteorologia Eduard Fontserè, Barcelona, 9 de noviembre de 1996.

Dotzek, N. and Friedrich, K., 2008: Downburst-producing thunderstorm in southern Germany: Radar analysis and predictability, Atmos Res, 93, 457-473, doi: 10.1016/j.atmosres.2008.09.034.

Hamid, K., 2012: Investigation of the passage of a derecho in Belgium, Atmos Res, 107, 86-105, doi: 10.1016/j.atmosres.2011.12.013.

Johns, R. H. and Doswell III, C. A., 1992: Severe Local Storms Forecasting, Weather Forecast, 7, 558-612.

Klingle, D. L., Smith, D. R., and Wolfson, M. M., 1987: Gust front characteristics as detected by Doppler radar, Mon Weather Rev, 115, 905-918.

Klock, R. and Mullock, J., 2001: Local Area Weather Manuals. Chapter 2: Aviation Weather Hazards, NAV Canada publications, http://www.navcanada.ca/ContentDefinitionFiles/ publications/lak/bc/BC31E-W.PDF. 
Lopez, J. M., 2007: A Mediterranean derecho: Catalonia (Spain), 17th August 2003, Atmos Res, 83, 272-283, doi: 10.1016/j.atmosres.2005.08.008.

Markowski, P. M. and Richardson, Y. P., 2010: Mesoscale Meteorology in Midlatitudes, Ed. John Wiley \& Sons, 430 pp.

McCann, W. D., 1994: Windex - A New Index for Forecasting Microburst Potential, Weather Forecast, 9, 532-541.

Mueller, C. K. and Carbone, R. E., 1987: Dynamics of a Thunderstorm Outflow, J Atmos Sci, 44, 1879-1898.

Pascual, R. and Callado, A., 2002: Mesoanalysis of recurrent convergence zones in north-eastern Iberian Peninsula, Proceedings of Second European Conference on Radar in Meteorology and Hydrology (ERAD), Delft, Holland, 18-22 November 2002.

Pineda, N., Aran, M., Andrés, A., Busto, M., Farnell, C., and Torà, M., 2009: Estudi de la pedregada del 17 de setembre de 2007 al Pla d'Urgell. Segona part: anàlisi meteorológica, Tethys, 6 , 83-102, doi: 10.3369/thetys.2009.6.06.

Pistotnik, G., Holzer, A. M., Kaltenböck, R., and Tschannett, S., 2011: An F3 downburst in Austria - A case study with special focus on the importance of real-time site surveys, Atmos Res, 100, 565-579, doi: 10.1016/j.atmosres.2010.10.011.

Rasmussen, E. N. and Blanchard, D. O., 1998: A Baseline Climatolohy of Sounding-Derived Supercell and Tornado Forecast Parameters, Weather Forecast, 13, 1148-1164.

Saltikoff, E., Koistinen, J., and Hohti, H., 2004: Downburst identification using Doppler shear in FMI radar network, Proceedings of Third European Conference on Radar in Meteorology and Hydrology (ERAD), Visby, Sweden, 6-10 September 2004, p. 4144.

Shen, J., Parks, E. K., and Bach, R. E., 1996: A Comprehensive Analysis of two Downburst related Aircraft Accidents, J Aircr, 33, 924-930.

Sigmet, 2011: IRIS ${ }^{T M}$ Product \& Display Manual, Version 8.12.9.

Wakimoto, R. M., 1985: Forecasting dry microburst activity over the High Plains, Mon Weather Rev, 113, 1131-1143.

Wilson, J. W. and Wakimoto, R. M., 2001: The Discovery of the Downburst: T.T. Fujita's Contribution, Bull Amer Meteorol Soc, 82, 49-62. 